\title{
The impact of the Journal of Homotopy and Related Structures
}

\author{
Martin Markl
}

Published online: 1 October 2013

(C) Tbilisi Centre for Mathematical Sciences 2013

While MathSciNet lists 73 journals containing "geometry" in their names (and noncommutativists among them even have their own Journal of Noncommutative Geometry), while topologists may choose from 21 journals, combinatorists from 23 journals, and algebraists from 61 journals covered by MathSciNet, there had been, until 1999, no journals focused on homotopy or homology theory, though these areas are blends of the above mentioned subjects, and there are more than 50 AMS classification codes covering various forms of homotopy or homology.

The mathematical community therefore welcomed the founding by Hvedri Inassaridze in 1999 of the journal "Homology, Homotopy and Applications". This followed in many ways the model of the electronic journal "Theory and Applications of Categories", founded in 1995. Refereeing followed the usual model for mathematical journals, but, crucially, actual publication online followed quickly on acceptance, usually within weeks.

Help with the print version was obtained from International Press, but Hvedri Inassaridze parted from them and in 2006 founded the "Journal of Homotopy and Related Structures", on an analogous model. This also has been a success, and widened the outlet for this burgeoning field, and its applications. This journal has recently been supported by Springer Verlag for the production and print version.

Both journals quickly found their places among respected journals keeping high standards and appreciated by the authors. This was also corroborated by the fact that both journals recently received impact factors, therefore publishing there does not

\section{Markl (凶)}

Mathematical Institute of the Academy, Žitná 25, 11567 Prague 1, Czech Republic

e-mail: mark1@math.cas.cz

\section{Markl}

MFF UK, Sokolovská 83, 18675 Prague 8, Czech Republic 
mean scientific suicide even for mathematicians coming from countries where the deadly scythe of Bibliometry is in full swing.

My personal experience with both journals is pretty pleasing, the refereeing process was always fast and also the actual publication followed quickly. This makes both journals particularly important for young scientists as they need today to satisfy Bibliometry by presenting published or at least accepted papers at the very beginning of their carriers.

I therefore congratulate Hvedri Inassaraidze on founding two successful journals which continue to keep high standards both in the scientific quality and in the publication process.

Martin Markl, Prague 